\title{
Teacher efficacy and attributes on the implementation of tiered instructional frameworks
}

\author{
Janet Alys Nichols ${ }^{1}$, William D. Nichols ${ }^{2}$, William H. Rupley ${ }^{3}$ \\ ${ }^{1}$ School of Education, Virginia Tech University, United States \\ ${ }^{2}$ College of Education \& Human Development, University of Maine, United States \\ ${ }^{3}$ Department of Teaching, Learning and Culture, Texas A\&M University, United States
}

\begin{tabular}{l}
\hline Article Info \\
\hline Article history: \\
Received Mar 27, 2020 \\
Revised Jun 22, 2020 \\
Accepted Jul 18, 2020 \\
\hline
\end{tabular}

\section{Keywords:}

Collective-efficacy

Evidenced-based practice

Self-efficacy

Teacher attributes

Tiered systems of support

\begin{abstract}
United States federal mandates and reforms to address the needs of at-risk students have resulted in many states being required to implement evidencebased practices (EBP) and tiered systems of support (TSS). We examined the relationships between successful implementation of EBP and tiered frameworks, specifically Positive Behavior Interventions and Support (PBIS) and the constructs of teacher self-efficacy, collective efficacy, and teacher attributions. Data were collected using the School-wide Evaluation Tool (SET), Teacher Self-Efficacy Scale (TSES), the Collective Efficacy Scale (CES), and Teachers' Attributions for Student Behavior Measure (TASBM). Significant correlations were found between PBIS implementation level and 1) Instructional Strategies subscale of the TSES; 2) Collective Efficacy Scale and both of its subscales; and 3) TASBM and its Stable and Blame subscales. Significant differences in mean ratings were found between high implementing schools and low implementing schools on the Instructional Strategies subscale of the TSES, on the CES, and both of its subscale. Results showed a decrease in mean ratings on the Blame subscale of the TASBM in schools that had higher implementation scores on the SET.
\end{abstract}

This is an open access article under the CC BY-SA license.

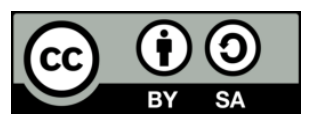

\section{Corresponding Author:}

William Dee Nichols,

College of Education \& Human Development,

University of Maine,

5749 Merrill Hall, Orono, ME 04469, United States.

Email: william.nichols1@ maine.edu

\section{INTRODUCTION}

Outcomes from interventions are directly impacted by the effectiveness of the teacher who is the primary implementer of interventions $[1,2]$. Teachers' self-efficacy and teachers' attributions for their students' successes and failures are prominent constructs for better understanding how teachers commit to and 1) try new instructional approaches, 2) work with at-risk learners, and 3) implement evidence-based interventions [3, 4]. Teachers' beliefs about their capabilities and their causal explanations for their students' successes and failures influence their perceptions about whether they can effectively implement evidence-based practices (EBP) and provide successful instruction for at-risk students [5]. Given that the implementation of interventions is determined by teachers' perceptions of their capabilities and how these directly impact students' success, it is important to understand the relationships between implementation of EBP that guide student learning and teacher self-efficacy, collective efficacy, and teacher attributions for students' success and failures. The purpose of this study is to examine how teacher self-efficacy, collective 
efficacy, and teacher attributions are related to the implementation of tiered systems of support, Positive Behavioral Interventions and Supports (PBIS).

The United States reauthorized the Individuals with Disabilities Education Improvement Act (IDEA) [6], which called for the identification, implementation and use of EBP to assist students with learning difficulties, as well as to determine eligibility for special education services [7]. The reformation of education called for practices to be tested for effectiveness using randomized, controlled trials and these practices, now identified as EBP, to be infused within interventions [8]. This movement called for educators to identify, disseminate, and implement practices that demonstrated increased student learning outcomes. Although the movement pushed for the implementation of evidence-based approaches, studies noted a substantial gap between research and the implementation and use of EBP in schools [9]. This gap between research on practices and implementation of practices in schools and classrooms limited the positive outcomes for children in schools [10].

Reviews of past intervention research focused on obstacles or barriers schools faced during program implementation that limited full implementation of targeted interventions [9, 11]. Researchers wanted to better understand the gap between research on EPB and the use of EPB in schools. Once identified, the barriers were organized into different categories within an ecological framework. The ecological framework of barriers has been divided into three different levels: macro, school, and individual [12].

At the macro level, barriers can consist of community factors including the educational system and the government [12]. Macro level decisions, such as the development of federal and statewide mandates, influence policies and financing of the implementation of EBP in schools. No Child Left Behind [13] and the reauthorization of IDEA [6] are federal education policies that significantly affected policies and practices implemented in education at the state level, including funding tied to required mandates. For example, these macro level mandates led to the adoption of TSS in the state of Maine intended to address the needs of at-risk students [14]. However, the policies and mandates, from the federal government, are often impeded during the implementation process. This can be caused by a lack of funds and a lack of resources that the state and school districts provide for the successful implementation and sustainability of the intervention [12]. The district level support of the adoption of TSS is critical in closing the implementation gap [15-17].

The second level in the ecological framework focuses on school-level factors. These factors include structures and policies of the organizational unit, school-based resources available to support interventions, and school climate [12]. School climate can include the perceptions faculty have about colleagues, administrators, and the student body [18]. Schools that have supportive administrators and leaders create an environment of high expectations, and create norms and values that are shared by most if not all teachers [19]. This type of environment allows for the formation of high collective efficacy. Other characteristics of school-level factors include mobility of students, size (large school versus small school), or setting (rural versus urban).

Level three in the ecological framework is represented by individual-level factors [12]. These factors involve a teacher's knowledge of classroom management strategies or preventative interventions geared to help at-risk students. The individual-level factors include the educational backgrounds and certifications of the faculty in a school. Psychological characteristics of teachers are vital in the implementation process. Psychological characteristics including depression, burn-out, and anxiety have an effect on the successful implementation of interventions. Teacher self-efficacy has been linked to emotional burnout and depersonalization and lower self-efficacy leads to higher rates of teacher burnout [19]. Educator attitudes and beliefs also impact the impacted the implementation process and fidelity of the intervention [20]. As beliefs and attitudes increased, the fidelity of the behavior interventions also increased.

Teachers' lack of experience or teachers' lack of familiarity when implementing new programs or interventions can lead to increased anxiety causing a reluctance to implement new programs [12]; thus, leading to lower efficacy and an avoidance of action as a means to reduce the negative response [3]. Teacher's perception of the ease of implementation and the usefulness of the intervention will either facilitate or hinder the implementation process [1]. Since the teacher is the primary implementer of EBP it is important to understand how individual factors influence implementation either positively or negatively with the purpose of reducing the implementation gap of EBP [1].

The ability for schools to address factors in the ecological framework during the implementation process could help facilitate the process and increase fidelity of the intervention. Failure to implement purposefully, most likely results in negative outcomes for the student, which in turn can support the belief that the intervention itself was not effective, when in reality it was non-systematic implementation that caused the negative outcomes [21,22] It is vital for teachers to be educated about the purpose of the intervention and process of implementation. Administrators need to be cognizant of the implementation gap as well as address barriers at the macro, school, and individual levels to produce positive student learning 
outcomes. Although it is important to understand the implications of barriers at all three ecological levels, the purpose of this study focused on barriers associated with school-level factors (collective efficacy), and individual-level factors (teacher self-efficacy and teacher attributions).

Self-efficacy is the belief in one's capabilities to produce positive outcomes, which leads to either action or non-action [3, 23]. These beliefs result in an individual's decision to act with the purpose of meeting the demands of the current task $[3,24,25]$. Self-efficacy is more than just knowing what to do in a specific situation; it is being able to organize and initiate appropriate steps and skills required to achieve a current goal [26]. Teacher self-efficacy is also a stable construct that does not change from the onset [27]. Furthermore, self-efficacy is a reliable predictor of human motivation, with higher levels predicting greater effort and persistence in the face of challenging tasks [3, 24, 28, 29] and extends beyond individual beliefs to include collective beliefs within an organization [28].

Self-efficacy focuses on an individual's beliefs about existing ability when faced with a task or a set goal. Collective efficacy, on the other hand, is concerned with both the collective group's beliefs about a task or goal and beliefs about how the group can work either in concert to achieve the goal or to meet the challenges of the task. Collective efficacy can either positively or negatively influence a group or organization's approach to a task, as well as the motivation for reaching collective goals, such as implementation of PBIS [4, 30].

Past research primarily focused on the association between teacher self-efficacy and collective efficacy and how these constructs related to positive student outcomes [19, 24-26, 28, 30-32]. Results supported that higher levels of teacher self-efficacy should lead to more innovative instruction due to increased levels of effort and persistence in producing successful outcomes and mastery experiences for learners [3]. Successful learner outcomes have shown a positive reciprocal relationship with teachers' selfefficacy; when student learning outcomes increase, teacher efficacy also increases [33]. Not only is an individual teacher's self-efficacy affected by positive student learning, schools with high collective efficacy tend to be more innovative in their use of teaching strategies and implementation of interventions targeted towards at-risk students [3, 34]. These two constructs teacher self-efficacy and school collective efficacy, positively impact each other. In addition, they positively influence the implementation process of schoolwide interventions such as PBIS.

In addition to measures of efficacy, researchers have studied the causal explanations of teachers about both positive and negative student outcomes [35-39]. These causal explanations have a strong potential to either positively or negatively affect the implementation of school wide interventions. According to Weiner [5] causal attributes fall along three dimensions: locus, stability, and control. Thus, actions can be seen as internal or external (locus), stable or unstable (stability), or controllable or uncontrollable (control). This three-dimensional model provides a basis for understanding how events or outcomes can be explained. For example, failure on an exam due to lack of studying is representative of an attributional profile that is internal-unstable-controllable. The decision not to study is an internal decision that is controllable due to the student's decision to not study. The action, not studying, is unstable because it can vary over time; choosing to study for the next test. However, if the failure is attributed to lack of ability this would be internal-stable-uncontrollable. Ability is considered an internal attribute, an innate characteristic, viewed as stable and not subject to student control. Consequently, the attributional profiles teachers assign to students can have positive or negative effects on classroom atmosphere [40]. A teacher who attributes academic failures of a learner to internal-stable-uncontrollable characteristics is likely to have different expectations than a teacher who attributes the learner profile to characteristics that are internal-unstable-controllable. If a profile includes a stable cause, teacher's expectancy for behavior change will be low. However, if the cause is unstable then there will be an increase in teacher expectancy to see a change in the student's behaviors.

The attributional profile that teachers assign to students as explanations for success or failure could be a barrier to the implementation process of schoolwide reform. Teachers who attribute failures (behaviorally or academically) to external causes, outside of the teacher's control (family issues or community issues), tend to neither accept responsibility for the failure nor choose to identify a different instructional approach to remediate failure [41-43]. In other words, teachers with profiles who attribute student outcomes to causes outside their control, or external locus of causality, are less likely to believe that the implementation of evidence-based practices will improve student performance. The consequences of lack of buy-in impede the implementation of such practices [42]. For these reasons, it is of great consequence to investigate whether teacher self-efficacy, collective efficacy, and teacher attributional profiles for their students' success and failures affect either positively or negatively the implementation of a tiered system of support (TSS).

The research question that guided this study was: Do the constructs of teacher self-efficacy, collective efficacy and attributional profiles of teachers account for variability in schoolwide implementation of Positive Behavior Intervention and Supports? 


\section{METHODS}

\subsection{Participants}

The sample was comprised of 96 females and 25 males who taught in large county district in the North Eastern United States. The range in age was 22-64, years teaching varied from .5 to 38, and years teaching in the current school was .5 to 38. All 121 teachers agreed to participate in the study. The participants had the following certifications: general elementary $(n=42)$, English/Language Arts $(n=$ 11), high school $(n=11)$, special education $(n=9)$, physical education $(n=6)$, world languages and art $(n=$ 7), and support staff including educational technician; librarian; guidance counselors $(n=4)$. A total of 121 teachers completed surveys; however, the number of questions answered by participants varied for each survey (Teacher Self-Efficacy Scale (TSES) $N=121$; Collective Efficacy Scale (CES) $N=119$; Teacher Attributions for Student Behaviors Measure (TASBM) $N=121$ ).

\subsection{Instrumentation}

School-Wide Evaluation Tool (SET). PBIS implementation level was assessed using the SchoolWide Evaluation Tool (SET) [44]. The purpose of the SET is to provide a rigorous fidelity measure of the primary prevention practices within a tiered system of support. The SET included interviews, school materials and documentation, and a walk through of the building. The tool consisted of seven sections that assessed implementation of practices: expectations defined, behavioral expectations taught, on-going system for rewarding behavioral expectations, system for responding to behavioral violations, monitoring and decision making, management, and district level support. An overall SET score of $80 \%$ and a score of $80 \%$ on the Behavioral Expectations Taught section represented full implementation. Horner et al. [44] reported the internal consistency of the SET to be high based on prior research conducted in 45 schools $(\alpha=.96)$.

Teacher Self-Efficacy Scale (TSES). Teacher self-efficacy, or the belief in the teacher's capability to educate all students, was measured using the Teacher Self-Efficacy Scale (TSES) [32]. The TSES was divided into three subscales: Student Engagement, Instructional Strategies, and Classroom Management. According to the guidelines each subscale can be used individually or combined as a measure of overall efficacy. The scale included 24 questions with responses on a 9-point Likert-type scale ranging from 1 (nothing) to 9 (a great deal). Internal consistency reliability was established in a study of in-service teachers, both for total score $(\alpha=.94)$ and for each subscale: $\alpha=.91$ for $\alpha=.87$ for student engagement, instructional strategies, $\alpha=.90$, and for classroom management [33]. Teachers complete the scale in a single sitting and take approximately 15 minutes to complete.

Collective Efficacy Scale (CES). Collective efficacy was measured with the Collective Efficacy Scale (CES) [30]. The Competency subscale was used to assess teachers' perceptions of their colleagues' ability to educate all students. The Task Analysis subscale measured external factors that could impede student achievement. These external barriers could be resources, building issues, and/or community level demographics. The scale included 21 questions and teachers rated their agreement on a 6-point Likert-type scale ranging from 1 (strongly disagree) to 6 (strongly agree). The scale was averaged with higher scores indicating higher collective efficacy and lower scores indicating lower efficacy. Goddard et al. [30] reported that internal consistency reliability of the scale was strong $(\alpha=.96)$.

Teachers' Attributions for Student Behavior Measure. An adaptive version of the Parent's Attributions for Child's Behavior Measure (PACBM) was used to measure teacher attributions [45]. The PACBM scale was adapted to change the focus from parents and children to teachers and students [46]. The Teachers' Attribution for Student Behavior Measure (TASBM) asked teachers to respond to scenarios describing disruptive, violent, and/or noncompliant behavior using Likert-type ratings. There were six scenarios and the same three attributional dimensions were assessed as in the parent measure. The teachers were instructed to imagine the situation and then rate their agreement with causal explanations of the student's behaviors on a 6 -point Likert type scale ( $1=$ strongly disagree; $6=$ strongly agree). Lower mean ratings were considered more positive, with higher mean ratings indicating the teacher had a more negative attributional style. A negative attributional style for teachers would include high scores on the blame and intentionality scale indicating the perception that students were in control of their behaviors. As mentioned above, this type of belief can lead to anger responses as well as punitive consequences [45].

\subsection{Procedures}

The study included two phases of data collection. The first phase consisted of conducting the School-Wide Evaluation Tool (SET) in which teachers at each school were observed and interviewed in their teaching environment based on the SET protocol. The second phase of data collection consisted of meeting with participants and distributing the surveys. The needs and schedule of each school dictated how the surveys were distributed. At three of the schools, the lead researcher met with teachers as a group for approximately 20 minutes to distribute and collect the completed surveys (TSES, CES, and PACBM). 
Also, gathered were informed consent and a completed individual teacher demographic questionnaire. Four of the schools provided time during a faculty meeting for the teachers to complete the surveys. The completed packets were placed in an empty envelope during the meeting. If teachers did not complete all surveys they were given an empty envelope and the lead researcher returned to the school a week later. Overall, 121 teacher surveys were collected from seven schools.

\section{RESULTS AND DISCUSSION}

\subsection{School-wide evaluation tool to address fidelity of implementation}

The mean score on the SET was used to indicate the extent to which each school was implementing schoolwide positive behavior supports with fidelity. Full implementation with fidelity is commonly referred to as a score of $80 / 80$. This score indicates that the school earned a mean score of $80 \%$ on the combined subscales and an $80 \%$ on the Behavioral Expectations Taught subscale. The information presented in Table 1 provides a summary of the scores calculated from the SET at the seven schools as well as the number of years' schools have been implementing PBIS. The percentages were calculated based on scores within each subscale, and subscale scores were then averaged to calculate the implementation score. Four out of the seven schools reached $80 \%$ or higher on the mean implementation score; however, none of the schools reached $80 \%$ or higher on the Behavioral Expectations Taught subscale, showing that all schools were only partially implemented at the time the SET was conducted. There was variability among the schools with regard to implementation scores as well as number of years.

Table 1. SET implementation scores

\begin{tabular}{|c|c|c|c|}
\hline School & YRS Implement & Mean & Behavioral Expectations Taught \\
\hline School 1 & $>6$ & $82 \%$ & $40 \%$ \\
\hline School 2 & 1 & $86 \%$ & $60 \%$ \\
\hline School 3 & $>5$ & $85 \%$ & $50 \%$ \\
\hline School 4 & $>5$ & $81 \%$ & $40 \%$ \\
\hline School 5 & $>3$ & $74 \%$ & $70 \%$ \\
\hline School 6 & $<1^{\mathrm{a}}$ & $66 \%$ & $20 \%$ \\
\hline School 7 & 3 & $67 \%$ & $20 \%$ \\
\hline
\end{tabular}

\subsection{Research question}

In order to answer the following question, we used correlational analyses and independent $t$-tests to examine differences between groups. Do the constructs of teacher self-efficacy, collective efficacy and teacher attributions account for variability in schoolwide implementation of Positive Behavior Intervention and Supports?

Teacher Self-Efficacy Scale (TSES). As previously mentioned, participants indicated on a 9-point Likert-type scale their belief in the amount of influence they have over different activities that impact learning and the classroom environment $(1=$ nothing, $3=$ very little, $5=$ some influence, $7=$ quite a lot, $9=a$ great deal). Cronbach's alpha for the scale was .93 indicating acceptable internal consistency. Cronbach's alpha was also computed for the three subscales associated with the TSES and all were found to have high internal consistency: Student Engagement $(\alpha=.88)$, Instructional Strategies $(\alpha=.86)$, and Classroom Management $(\alpha=.86)$. The mean score for the TSES was $7.27(S D=.76)$. The mean rating for Student Engagement subscale was $6.89(S D=1.01)$ and the Instructional Strategies subscale was $7.47(S D=.84)$ and the mean rating for Classroom Management subscale was $7.48(S D=.87)$. Correlations were computed between the TSES and mean score on the SET for PBIS implementation, as well as correlations between the TSES and the Behavioral Expectations Taught subscale from the SET. As noted in Table 2, the Pearson product-moment correlation was not significant between implementation scores and teacher efficacy, indicating that overall teacher efficacy did not vary by implementation level. The TSES has three subscales and correlations were computed between the SET and each of the subscales. As can also be seen in Table 4, the relationship between the Instructional Strategies subscale and implementation level was significant with teacher beliefs in their ability to use various teaching strategies accounting for $4 \%$ of the variance in implementation level. The correlations between PBIS implementation level and the two other TSES subscales, student engagement and classroom management, were not significant. 
Table 2. Correlations between teacher efficacy and implementation

\begin{tabular}{ccc}
\hline Measures & $\begin{array}{c}\text { School Wide Evaluation Tool } \\
\text { SET }\end{array}$ & BET \\
\hline Teacher Efficacy & & \\
TSES & .17 & .15 \\
Student Engagement & .12 & .17 \\
Instructional Strategies & $.20^{*}$ & .13 \\
Classroom Management & .10 & .09 \\
${ }^{*} p<.05$. & &
\end{tabular}

Implementation of PBIS was measured by the mean score on both the SET and the Teaching Behavioral Expectations subscale. Table 3 results show that there were no significant correlations between the Behavioral Expectations Taught subscale and the total TSES and its subscales. This indicates that efficacy did not vary for implementation scores based on teaching behavioral expectations. Further analysis revealed differences in mean efficacy ratings for participants at schools with an implementation mean score of 80 or above and participants at schools with an implementation mean score below 80. An independent $t$ test was computed to determine if there were significant differences in mean efficacy ratings for high versus low implementing schools. As displayed in Table 3, the $t$-test was not significant for overall efficacy. It did however, show a significant difference between implementation levels on mean efficacy ratings related to instructional strategies. Specifically, teachers working at schools with higher levels of implementation of PBIS reported more confidence in their abilities to use various instructional practices aimed at producing positive student outcomes than teachers working in lower implementing schools.

Table 3. implementation levels and teacher efficacy

\begin{tabular}{ccccc}
\hline Measures & Hi Implementation $M(S D)$ & Low Implementation $M(S D)$ & $t$-test & $P$ \\
\hline TSES & $7.41(.60)$ & $7.22(.86)$ & 1.5 & 0.14 \\
Student Engagement & $6.96(.85)$ & $6.90(1.10)$ & 0.59 & 0.56 \\
Instructional Strategies & $7.68(.70)$ & $7.35(.89)$ & 2.13 & 0.04 \\
Classroom Management & $7.56(.71)$ & $7.43(.97)$ & 0.81 & 0.42 \\
\hline
\end{tabular}

Collective Efficacy Scale (CES). Cronbach's alpha for the scale was .88 indicating adequate reliability for the total scale. Cronbach's alpha was also computed for the two subscales and both were found to have high internal consistency: Competency subscale $(\alpha=.85)$ and Task Analysis $(\alpha=.67)$. The mean rating for CES was $4.10(S D=.64)$ and subscales: Competency $(M=4.33, S D=.68)$; Task Analysis $(M=$ $3.44, S D=.67)$. Pearson product-moment correlations were computed between implementation levels and mean ratings of collective efficacy. The results of this correlation analyses are noted in Table 4. Significant positive correlations between PBIS implementation level and the total CES and its subscales indicate that collective efficacy increased with higher levels of implementation level of PBIS. Although the correlation coefficients were significant, the effect sizes were moderate [47], with collective efficacy ratings accounting for $14 \%$ to $18 \%$ of the variance in the implementation level of PBIS.

Table 4. Correlations between collective efficacy and implementation

\begin{tabular}{ccc}
\hline Measures & \multicolumn{2}{c}{ School Wide Evaluation Tool } \\
& SET & BET \\
\hline CES & $.43^{* *}$ & $.25^{* *}$ \\
Competency & $.41^{* *}$ & $.25^{* *}$ \\
Task Analysis & $.37^{* *}$ & $.19^{*}$ \\
\hline${ }^{*} p<.05 .{ }^{* *} p<.01$. & &
\end{tabular}

Pearson product-moment correlations were also computed between the mean score on the Behavioral Expectations Taught subscale from the SET and the CES and its two subscales: Competency and Task Analysis. Significant positive correlations were found between Behavioral Expectations Taught and the CES and the Competency and Task Analysis subscales, indicating that teachers with higher collective efficacy ratings tended to be in schools with higher scores on Behavioral Expectations Taught. Although the correlation coefficients were significant, the effect sizes were small [47] with collective efficacy ratings accounting for only $4 \%$ to $6 \%$ of the variance in the mean scores for Behavioral Expectations Taught subscale. Next, an independent $t$-test was computed to determine if the mean ratings of collective efficacy, 
the total scale and subscales, were significantly different when examining high implementation level $(>80)$ schools versus low implementation level $(<80)$ schools. Table 5 displays that teachers working in schools with higher implementation levels had higher mean ratings for collective efficacy when compared with teachers working at schools with lower implementation levels. The effect size for this analysis was large [47].

Table 5. Implementation levels and collective efficacy

\begin{tabular}{cccccc}
\hline Measures & Hi Implementation $M(S D)$ & Low Implementation $M(S D)$ & $t$-test & $P$ & Cohen's d \\
\hline CES & $4.41(.61)$ & $3.88(.56)$ & 4.92 & 0.001 & .91 \\
Competency & $4.63(.61)$ & $4.11(.64)$ & 4.56 & 0.001 & .83 \\
Task Analysis & $3.72(.72)$ & $3.23(.54)$ & 4.07 & 0.001 & .77 \\
\hline
\end{tabular}

Lastly, we computed mean ratings for collective efficacy organized by school. Schools one, two, three, and four were categorized as high implementing schools and schools five, six, and seven were categorized as low implementing schools based on their SET scores. The mean collective efficacy ratings for high implementing schools ranged from $3.70(S D=.62)$ to $5.1(S D=.36)$ and the mean ratings for the low implementing schools ranged from $3.71(S D=.58)$ to $4.06(S D=.53)$. Figure 1 shows the differences in collective efficacy ratings and implementation level organized by school. The results revealed a trend for greater mean ratings for collective efficacy at school with higher implementation scores. CES mean ratings for each school organized by the implementation level at the school (HI versus Lo). CES = Collective Efficacy Scale; HI = mean score of above 80 on the School Wide Evaluation Tool; Lo = mean score of below 80 on the School Wide Evaluation Tool; S3 = School 3; S4 = Schools 5; S1 = School 1; S2 = School 2; S5 = School 5; S6 = School 6; S7 = School 7.

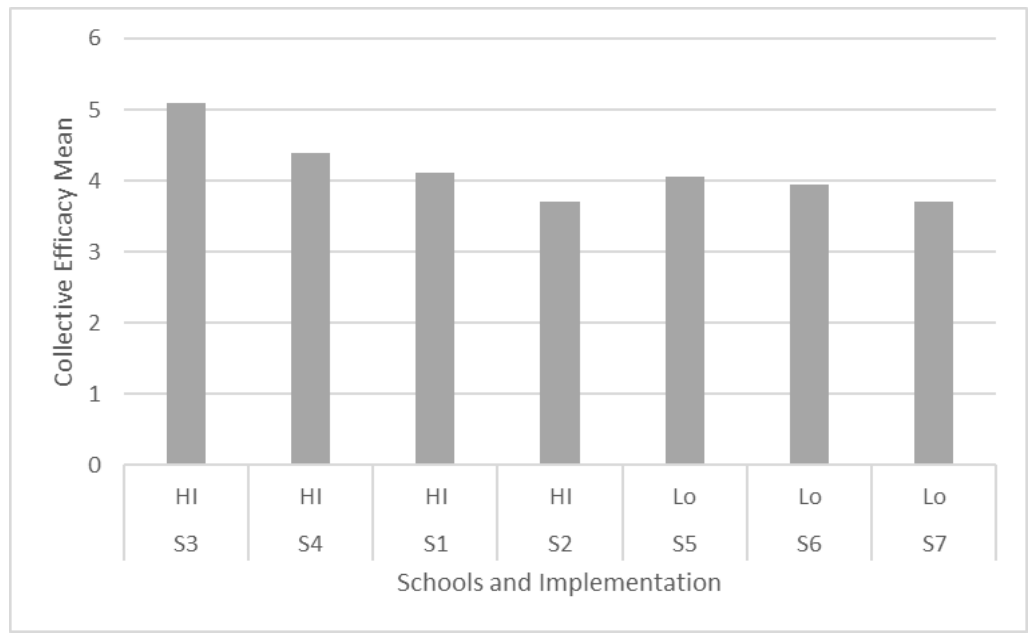

Figure 1. Differences in collective efficacy ratings and implementation level organized by school

Teachers' Attributions for Student Behavior Measure (TASBM). Cronbach's alpha for the overall scale was .95 indicating acceptable internal consistency. Cronbach's alpha was also computed for the three subscales and all were found to have high internal consistency: Internal subscale $(\alpha=.92)$, Stable subscale $(\alpha$ $=.91)$, and Blame subscale $(\alpha=.93)$. The mean rating for the TASBM was $2.99(S D=.85)$. The mean rating on the Stable subscale was $2.24(S D=.76)$, the mean rating for the Internal subscale was $2.86(S D=1.05)$, and the mean rating for the Blame subscale was $3.57(S D=1.16)$. Table 6 is the computed correlations between implementation level scores from the SET and the TASBM and three subscales. Significant negative correlations were found between the total TASBM scale and implementation level as well as between the Stable subscale and Blame subscale. The results indicated that teacher attribution ratings varied with implementation level. As implementation level increased, teacher attribution ratings declined indicating more positive attributions for student behaviors. Although the correlation coefficients were significant, the effect sizes were small [47], with teacher attribution ratings accounting for only $3 \%$ to $8 \%$ of the variance in the implementation of PBIS. 
Table 6. Correlations between teacher attributions and implementation

\begin{tabular}{ccc}
\hline \multirow{2}{*}{ Measures } & \multicolumn{2}{c}{ School Wide Evaluation Tool } \\
& SET & BET \\
\hline TASBM & $-.21^{*}$ & $-.26^{* *}$ \\
Internal & -.06 & -.15 \\
Stable & $-.18^{*}$ & $-.25^{* *}$ \\
Blame & $-.28^{* *}$ & $-.27^{* *}$ \\
\hline${ }^{*} p<.05 .{ }^{* *} p<.001$. & &
\end{tabular}

Pearson product-moment correlations were computed between the mean score on the Behavioral Expectations Taught subscale and the TASBM as well as the three subscales. Significant negative correlations were found between Behavioral Expectations Taught and the TASBM as well as the Stable and Blame subscales. These results shown in Table 7, indicate that with increased mean scores on the Behavioral Expectations Taught, teacher attribution ratings decreased. As stated previously, lower attribution ratings indicated positive teacher attributions towards student behaviors. Although the correlation coefficients were significant, the effect sizes were small [47], with teacher attribution ratings accounting for only $6 \%$ to $7 \%$ of the variance of the scores in the Behavioral Expectations Taught subscale.

Table 7. Correlations between teacher attributions and implementation

\begin{tabular}{ccc}
\hline \multirow{2}{*}{ Measures } & \multicolumn{2}{c}{ School Wide Evaluation Tool } \\
& SET & BET \\
\hline TASBM & $-.21^{*}$ & $-.26^{* *}$ \\
Internal & -.06 & -.15 \\
Stable & $-.18^{*}$ & $-.25^{* *}$ \\
Blame & $-.28^{* *}$ & $-.27^{* *}$ \\
\hline${ }^{*} p<.05 .{ }^{* *} p<.001$. & &
\end{tabular}

Further analysis investigated differences in teacher attribution ratings between higher and lower levels of implementation. As shown in Table 8, the independent $t$-test revealed no significant mean differences between the TASBM, Internal subscale, and Stable subscale for high versus low implementing schools. However, the mean difference on the Blame subscale between high levels of implementation and lower levels of implementation was significant. This indicated that teachers who worked at schools with higher levels of implementation of PBIS tended to have lower ratings for attributions associated with blaming the students for their challenging behaviors.

Table 8. Implementation levels and teacher attributions

\begin{tabular}{ccccc}
\hline Measures & Hi Implementation $M(S D)$ & Low Implementation $M(S D)$ & $t$-test & $P$ \\
\hline TASBM & $2.83(.84)$ & $3.07(.84)$ & -1.56 & 0.12 \\
Internal & $2.85(1.12)$ & $2.84(1.03)$ & 0.07 & 0.94 \\
Stable & $2.14(.67)$ & $2.32(.81)$ & -1.30 & 0.20 \\
Blame & $3.27(1.17)$ & $3.79(1.11$ & -2.49 & 0.01 \\
\hline
\end{tabular}

\subsection{Discussion}

The purpose of this study was to examine factors that either positively or negatively influence the implementation of evidence-based practices such as Positive Behavior Intervention and Supports (PBIS). Although there can be many factors that impact intervention implementation occurring at the macro, school, and individual level of an ecological framework, this study focused primarily on school-level and individuallevel factors associated with self-efficacy, collective efficacy and teacher attributions for their students' successes and failures. Domitrovich et al. [12] identified factors at the macro level (e.g., community, educational system and government decisions) that impact implementation of evidence-based practices; however, it was the intent of this study to examine barriers at the school-level (e.g., collective efficacy individual-level efficacy, teacher self-efficacy, and teacher attributions).

The group-level factor of collective efficacy as measured by the CES [48] reflects the perceptions of teachers in a school that their effort and persistence as one unit will have positive effects on student outcomes. Collective efficacy can influence the collaborative climate of the school and the interventions being implemented [48]. By understanding the role teachers' confidence in their colleagues' teaching abilities, as well as the teachers' perceptions concerning the student body and community characteristics play in the implementation process, recommendations can be made to increase the implementation fidelity of PBIS [18].

Int. J. Eval. \& Res. Educ. Vol. 9, No. 3, September 2020: 731 - 742 
Along with group-level factors such as collective efficacy, individual-level factors within the ecological framework are important to consider during the intervention implementation process [12]. Factors including individuals' training in classroom management or preventative programs, educational level, certification, and psychological characteristics all play a role in the implementation process. Since the teacher is the primary implementer of evidence-based practices (EBP) it is important to understand whether teacher-level factors such as self-efficacy and teacher attributions, are associated with implementation either positively or negatively [1]. The results of this study have implications for schools that are already implementing PBIS, or are embarking on such implementation. A deeper level of understanding regarding the relationships between the implementation processes and factors such as self-efficacy, collective efficacy and teacher attributions should assist schools in effective intervention implementation.

In this study, the relationship between teacher self-efficacy and the implementation process of PBIS was significant but weak. There was not a significant correlation between implementation level and composite ratings on the TSES. However, the results showed a positive relationship between the Instructional Strategies subscale and implementation level. This relationship indicated that level of confidence teachers expressed in their ability to use various instructional strategies was associated with higher levels of implementation scores. Two credible explanations for this finding are: 1) either the adoption of PBIS, which includes an emphasis on teaching prosocial skills and expected behaviors, may have increased teacher selfefficacy; 2) or the teachers who already had high efficacy in the area of instructional strategies were able to adopt the principles of PBIS more easily.

To determine differences in efficacy ratings between high implementing schools, scores of 80 or above, and low implementing schools, scores of 79 and below, an independent $t$-test was computed. The results did not reveal a significant difference for the total scale when comparing high versus low implementing schools but did yield a significant difference in ratings of efficacy on the Instructional Strategies subscale. This indicated that participants who were working at schools that had higher levels of implementation of PBIS had more confidence in their abilities to use innovative teaching practices in order to produce positive student outcomes

Previous research found that collective efficacy defined as strong ties to teacher networks and colleagues influenced positively implementation of the processes, which in turn influenced positive student outcomes [49]. We found a modest relationship between PBIS implementation level and perceived collective efficacy, indicating that participants at schools with higher levels of implementation had stronger beliefs of confidence in their colleague's abilities to teach all students. Participants at schools with higher versus lower levels of implementation of PBIS were more likely to believe that external factors, such as community issues, family issues, or school resources, would not be obstacles to educating all students. Although a statement regarding the direction of causality cannot be made, a previous study found that the implementation of PBIS increased the organizational health and climate of the schools [50]. PBIS training could foster a positive and collaborative work environment that encourages the belief that colleagues were competent in teaching all students, which increased collective efficacy [51].

PBIS is a system that defines and teaches positive behavioral supports for all students [52]. We found that as the implementation ratings increased, teacher attributions became more positive. Also, there was a significant difference in ratings on the Blame subscale between higher implementing schools and lower implementing schools. Teachers in schools with higher levels of implementation blamed the students less often for maladaptive behaviors than in schools with lower implementation scores. Teachers in schools who adopt the PBIS philosophy are trained in the use of positive behavioral supports and to use many tools to change and influence students' behaviors in a positive non-punitive manner [7]. The difference in ratings for blaming the student may have indicated that teachers from schools that had higher levels of implementation had also adopted a positive non-blaming attitude towards student behaviors.

\section{CONCLUSION}

Barriers to implementation can occur at three different levels. This study focused on the barriers at the individual-level and the school-level. Many schools adopt or begin the implementation process only to abandon the implementation of the EBP. The findings from this study indicated that the higher rating of confidence in fellow peers was also related to higher implementation scores on the SET. There is a reciprocal relationship between collective efficacy and teacher leadership. This relationship contributes to teachers' willingness to offer assistance, share expertise through professional development, and lead beyond the classroom. Identifying teachers who have this willingness to lead beyond the classroom could have a profound effect on the interventions used within a school and the successful implementation of evidencebased practices. PBIS requires a team approach for implementation and is a schoolwide model that requires participation from all faculty and staff in the school. If schools have a negative social climate it creates 
resistance toward implementation of tiered systems of support such as PBIS. Negative social climates within schools limit the staff buy-in and productive training sessions that ultimately impede the implementation process. Including faculty in the decision-making process, keeping staff informed of the progress each month and celebrating faculty and staff participation helps overcome resistance to implementation. School administrators and staff may want to consider using coaches and trainers at the onset and throughout the implementation process to ensure that staff is involved and well informed. The teachers in this study reported they had high personal efficacy; however, as indicated by the findings, collective efficacy varied with implementation. Improving the overall perceived belief in the capabilities of the faculty can have positive effects on student outcomes. The results indicated that teachers believed that they, as individuals, knew how to handle challenging or disruptive behavior; however, over $76 \%$ of the participants believed that their colleagues needed more training in dealing with challenging student behaviors. The participating teachers did not have the confidence in their colleagues' abilities to meet the needs of students with disruptive behaviors. Attitudes and beliefs impact the implementation of a school-wide intervention. Therefore, improving the attitudes and beliefs of the teachers and their trust in each other could increase implementation of evidenced-based practices.

There are multiple variables that could impact implementation of instructional interventions. This study focused on three constructs: teacher self-efficacy, collective efficacy, and teacher attributions. Due to the complexity of schools and administrative structures it is difficult to disentangle relationships between multiple variables with correlation analysis. By changing the data collection structure and research design, more powerful statistical analyses could be used to highlight the changes in these three constructs by establishing a baseline on ratings. The correlational analyses in the present study suggested relationships between variables but did not allow for the conclusion that one variable led to a change in another variable. Future research should include multiple data collection points during the implementation process to determine the effect of PBIS on teacher self-efficacy, collective efficacy, and teacher attributions. A quasiexperimental research design with pre-test/post-test would investigate the differences between schools that have implemented PBIS and those that have not implemented PBIS. Data could be collected at the beginning of implementation for both groups of schools and then a year later to determine changes in the variables. The results from this type of design could indicate if schools began the implementation process with high levels of self-efficacy or collective efficacy or if implementation of PBIS led to an increase in self-efficacy or collective efficacy.

In conclusion, participants' confidence in their use of effective instructional strategies, higher levels of collective efficacy, and positive attributions were associated with higher levels of implementation of PBIS as reported by the SET. A causal relationship could not be established between implementation and the three constructs. In addition, it did not determine if self-efficacy, collective efficacy, and teacher attributions were barriers to implementation. However, the study did establish the relationship between these variables indicating their connection to the implementation process. Understanding the relationships between teacher self-efficacy, collective efficacy, and teacher attributional profiles as well as the connection to PBIS will only enhance schools' ability to reach full implementation.

\section{REFERENCES}

[1] Forman, S. G., Innovation implementation: Developing leadership for evidence- based practice. In S. Rosenfeld \& V. Berninger (Eds.), Translating science-supported instruction into evidence-based practices: Understanding and applying the implementation process. New York, NY: Oxford University Press, pp. 655-676, 2009.

[2] Heck, R. H., "Teacher effectiveness and student achievement: Investigating a multilevel cross-classified model," Journal of Educational Administration, vol. 47, no. 2, pp. 227-249, 2009.

[3] Bandura, A., Self-efficacy: The exercise of control. New York: W.H. Freeman, 1997.

[4] Zee, M. and Koomen, H. E. Y., "Teacher self-efficacy and its effects on classroom processes, student academic adjustment, and teacher well-being: A synthesis of 40 years of research," Review of Educational Research, vol. 86, no. 4, pp. 981-1015, 2016.

[5] Weiner, B., "An attributional theory of achievement motivation and emotion," Psychological Review, vol. 92, no. 4 pp. 548-573, 1985.

[6] Individuals with Disabilities Education Improvement Act, 20 U.S.C. 1400, 2004.

[7] Sugai, G. and Horner, R. R., "A Promising Approach for Expanding and Sustaining School Wide Positive Behavior Support," School Psychology Review, vol. 35, no. 2, pp. 245-259, 2006.

[8] Kelly, B., "Implementation science for psychology in education," in D. F. Kelly, Barbara, and Perkins, Ed., Handbook of implementation science for psychology in education, Cambridge University Press, 2012.

[9] G. Forman, et al., "Implementation science and school psychology," School psychology quarterly: The official Journal of the division of school psychology, American Psychological Association, vol. 28, no, 2, pp. 77-100, 2013.

[10] Fixsen, D. L., et al., Implementation Research: A Synthesis of the Literature. Tampa, FL: University of South Florida, Louis de la Parte Florida Mental Health Institute, The National Implementation Research Network, 2005. 
[11] Durlak, J. A. and DuPre, E. P., "Implementation matters: A review of research on the influence of implementation on program outcomes and the factors affecting implementation," American Journal of Community Psychology, vol. 41, no. 3, pp. 327-350, 2008.

[12] Domitrovich, C. E., et al., "Maximizing the implementation quality of evidence-based preventive interventions in schools: A conceptual framework," Advances in School Mental Health Promotion, vol. 1, no. 3, pp. 6-28, 2008.

[13] No Child Left Behind. No Child Left Behind Act of 2001. In No Child Left Behind. U.S. Department of Education, 2002. [Online]. Available: http://www.nclb.gov/start/facts/achievement_aa.html

[14] Maine Unified Special Education Regulation (MUSER), Maine Department of Education, 05-071, Chapter 101, 2011.

[15] Cook, B. and Odom, S., "Evidenced-based practices and implementation science in special education," Exceptional Children, vol. 79, no. 2, pp. 135-144, 2013.

[16] Horner, R., et al., "Scaling up school-wide positive interventions and supports: Experiences of seven states with documented success," Journal of Positive Behavior Interventions, vol. 16, no. 4, pp. 197-208, 2014.

[17] Nese, R. N. T., et al., "Predicting abandonment of school-wide positive behavior support interventions," Behavioral Disorders, vol. 42, no. 1, pp. 261-270, 2016.

[18] Hoagwood, K. and Johnson, J., "School psychology: A public health framework," Journal of School Psychology, vol. 41 , no. 1 , pp. 3-21, 2003

[19] Skaalvik, E. M. and Skaalvik, S., "Teacher self-efficacy and teacher burnout: A study of relations," Teaching and Teacher Education, vol. 26, no. 4, pp. 1059-1069, 2010.

[20] Cook, C. R., et al., "A supportive beliefs intervention to facilitate the implementation of evidence-based practices within a multi-tiered system of supports," School Mental Health: A Multidisciplinary Research and Practice Journal, vol. 7, no. 1, pp, 49-60, 2015.

[21] Aarons, G. A. and Palinkas, L. A., "Implementation of evidence-based practice in child welfare: Service provider perspectives," Administration and Policy in Mental Health and Mental Health Services Research, vol. 34, no. 4, pp. 411-419, 2007.

[22] Sanetti, L. M. H. and Collier-Meek, M. A., "Data-driven delivery of implementation supports in a multi-tiered framework: a pilot study: Multi-tiered implementation supports," Psychology in the Schools, vol. 52, no. 8, pp. 815-828, 2015.

[23] Ormrod, J. E., Educational Psychology: Developing Learners (5th ed.). Glossary. N.J. Merrill: Upper Saddle River, 2006.

[24] Bandura, A., "Self-efficacy: Toward a unifying theory of behavioral change," Psychological Review, vol. 84, no. 2, pp. 191-215, 1977.

[25] Bandura, A., "Self-efficacy mechanism in human agency," American Psychologist, vol. 37, no. 2, pp. 122-147, 1982.

[26] Bandura, A. and Schunk, D. H., "Cultivating competence, self-efficacy, and intrinsic interest through proximal selfmotivation," Journal of Personality and Social Psychology, vol. 41, no. 3, pp. 586-598, 1981.

[27] Künsting Josef, Neuber, V., and Lipowsky, F., "Teacher self-efficacy as a long-term predictor of instructional quality in the classroom," European Journal of Psychology of Education: A Journal of Education and Development, vol. 31, no. 3, pp. 299-322, 2016.

[28] Bandura, A., "Social cognitive theory: An agentic perspective," Annual Review of Psychology, vol. 52, no. 1, pp. 1-26, 2001.

[29] Ross, J. and Bruce, C., "Professional development effects on teacher efficacy: Results of randomized field trial," The Journal of Educational Research, vol. 101, no. 1, pp. 50-60, 2007.

[30] Goddard, R. D., Hoy, W. K., and Hoy, A. W., "Collective teacher efficacy: Its meaning, measure, and impact on student achievement," American Educational Research Journal, vol. 37, no. 2, pp. 479-507, 2000.

[31] McCoach, D. B. and Colbert, R. D., "Factors underlying the collective teacher efficacy scale and their mediating role in the effect of socioeconomic status on academic achievement at the school level," Measurement and Evaluation in Counseling and Development, vol. 43, no. 1, pp. 31-47, 2010.

[32] Tschannen-Moran, M., Hoy, A. W., and Hoy, W. K., "Teacher Efficacy: Its meaning and Measure," Review of Educational Research, vol. 68, no. 2, pp. 202-248, 1998.

[33] Tschannen-Moran, M. and Woolfolk Hoy, A., "Teacher efficacy: Capturing an elusive construct," Teaching and Teacher Education, vol. 17, no. 7, pp. 783-805, 2001.

[34] Fransson, G. and Frelin A., "Highly committed teachers: What makes them tick? A study of sustained commitment," Teachers and Teaching, vol. 22, no. 8, pp. 896-912, 2016.

[35] Andreou, E. and Rapti, A., "Teachers' causal attributions for behaviour problems and perceived efficacy for class management in relation to selected interventions," Behaviour Change, vol. 27, no. 1, pp. 53-67, 2010.

[36] Brady, K. and Woolfson, L., "What teacher factors influence their attributions for children's difficulties in learning?" The British Journal of Educational Psychology, vol. 78, no. 4, pp. 527-544, 2008.

[37] Carter, L. M., et al., "Reliability and validity of a measure of preschool teachers' attributions for disruptive behavior," Early Education and Development, vol. 25, no. 7, pp. 949-972. 2014.

[38] Hughes, J. N., Barker, Donald, Kemenoff, Sylvia, and Hart, M., "Problem ownership, causal attributions, and selfefficacy as predictors of teachers," Journal of Educational Administration, vol. 4, no. 4, pp. 369-384, 1993.

[39] Rolison, M. A. and Medway, F. J., "Teachers' Expectations and Attributions for Student Achievement: Effects of Label, Performance Pattern, and Special Education Intervention," American Educational Research Journal, vol. 22, no. 4, pp. 561-573, 1985 . 
[40] Weiner, B., "The development of an attribution-based theory of motivation: A history of ideas," Educational Psychologist, vol. 45, no. 1, pp. 28-36, 2010.

[41] Alter, P., Walker, J., and Landers, E., "Teachers' perceptions of students' challenging behavior and the impact of teacher demographics," Education and Treatment of Children, vol. 36, no. 4, pp. 51-69, 2013.

[42] Ding, M., Li, Y., Li, X., and Kulm, G., "Chinese teachers' attributions and coping strategies for student classroom misbehavior," Asia Pacific Journal of Education, vol. 30, no. 3, pp. 321-337, 2010.

[43] Soodak, L. C. and Podell, D. M., "Teachers' thinking about difficult-to-teach students," Journal of Educational Research, vol. 88, no. 1, pp. 44-51, 1994.

[44] Horner, R. H., et al., "The school-wide evaluation tool (SET): A research instrument for assessing school-wide positive behavior support," Journal of Positive Behavior Interventions, vol. 6, no. 1, pp. 3-12, 2004.

[45] Sanders, M. R., Pidgeon, A. M., Gravestock, F., Connors, M. D., Brown, S., and Young, R. W., "Does parental attributional retraining and anger management enhance the effects of the Triple P-Positive Parenting Program with parents at risk of child maltreatment?" Behavior Therapy, vol. 35, no. 3, pp. 513-535, 2004.

[46] Simms, A. P., "The relationship between teachers' causal attributions for student problem behavior and teachers' intervention preferences," ProQuest Dissertations and Thesis Database, 2014.

[47] Cohen, J., Statistical power analysis for the behavioral sciences (2nd ed.). Hillsdale, N.J: L. Erlbaum Associates, 1988.

[48] Goddard, R. D., "Collective Efficacy: A Neglected Construct in the Study of Schools and Student Achievement," Journal of Educational Psychology, vol. 93, no. 3, pp. 467-476, 2001.

[49] Moolenaar, N. M., Sleegers, P. J. C., and Daly, A. J., "Teaming up: Linking collaboration networks, collective efficacy, and student achievement," Teaching and Teacher Education, vol. 28, no. 2, pp. 251-262, 2012.

[50] Bradshaw, C. P., et al., "The impact of school-wide positive behavioral interventions and supports (PBIS) on the organizational health of elementary schools," School Psychology Quarterly, vol. 23, no. 4, pp. 462-473, 2008.

[51] Ross, S. W., Romer, N., and Horner, R. H., "Teacher well-being and the implementation of school-wide positive behavior interventions and supports," Journal of Positive Behavior Interventions, vol. 14, no. 2, pp. 118-128, 2012.

[52] Molloy, L. E., Moore, J. E., Trail, J., Van Epps, J. J., and Hopfer, S., "Understanding real-world implementation quality and "active ingredients" of PBIS," Prevention Science, vol. 14, no. 6, pp. 593-605, 2013. 